\title{
中华卵索线虫雌雄寄生后期幼虫基因差异表达分析
}

\author{
吴运梅，张丽红，王国秀* \\ (华中师范大学生命科学学院 遗传调控与整合生物学湖北省重点实验室, 湖北 武汉 430079)
}

\begin{abstract}
摘要: 索科线虫是一类具有很大生防潜力的昆虫(如棉铃虫等)天敌资源，但由于其体外培养尚未获得成功， 阻碍了商业化生产和大规模应用, 究其原因主要是体外培养的线虫不能完成雌雄性别分化。因此, 研究该类 线虫性别分化机制成为近年本领域的热点课题。该文以中华卵索线虫为实验材料, 采用 mRNA 差异显示的方法, 分析了中华卵索线虫性别分化关键时期雌、雄寄生后期幼线虫的基因表达差异。在雌雄线虫体内得到具有表达差 异的基因片段 20 条。其中 8 条在雄虫体内特异性表达, 12 条在雌虫体内特异性表达。利用信息生物学技术对所分 离到的差异片段进行了序列分析。其中, Ensembl 分析发现 4 个片段与秀丽线虫 X 染色体具有可匹配片段, 推测这 些片段可能是影响中华卵索线虫性别分化的重要基因。这些结果将为后续研究提供思路。
\end{abstract}

关键词: 昆虫病原索科线虫; 性别分化; mRNA 差异显示

中图分类号: Q959.171; Q344.2; S476.15 文献标志码: A 文章编号：0254-5853-(2012)05-0487-06

\section{Analysis of differentially expressed genes from female and male postparasitic Ovomermis sinensis juveniles}

\author{
WU Yun-Mei, ZHANG Li-Hong, WANG Guo-Xiu*
}

(Hubei Key Laboratory of Genetic and Integrative Biology, College of Life Sciences, Huazhong Normal University, Wuhan 430079, China)

\begin{abstract}
Mermithidae, as an important natural predator of pests such as Bollworm, has great potential for natural biological control of invasive pests. Unfortunately, the in vitro culture of the nematode has not yet been successful, delaying the commercial application of this pest control method. The key reason for this failure is the inability of the worms to accomplish sex differentiation, sparking a strong interest in this process. Here, we analyzed the differences in gene expression of female and male postparasitic Ovomermis sinensis juveniles by mRNA differential display. In total, 20 gene fragments that had differential expression in male and female worms were isolated, including 8 male- and 12 female-specific ones. Bioinformatics methods were employed to analyze sequences of these fragments, in which ensembl analysis shows 4 fragments have comparable parts with $C$. elegence's $\mathrm{X}$ chromosome, we speculate those fragments are important genes which influence sex differentiation of Ovomermis sinensis, This data provides an idea for further study of the molecular mechanism of sex differentiation in mermithids.
\end{abstract}

Key words: Mermithidae; Sexual differentiation; mRNA differentially display

中华卵索线虫(Ovomermis sinensis Chen)是昆虫 病原索科线虫的一种, 属无尾感器纲(Aphasmidia)嘴 刺目 (Enoplida) 索线虫科 (Mermithidae) 卵索属 (Ovomermis)(Chen et al, 1991), 广泛寄生于鳞翅目 昆虫体内, 如斜纹夜蛾、甜菜夜蛾、菜青虫、黄地 老虎、小地老虎及棉铃虫等, 其感染期幼线虫可主 动寻找并侵染宿主, 寄生后导致宿主不育, 并因脱
出使宿主体壁破裂而死亡。因此，害虫的寄生率即 等于其死亡率 (Zhong \& Wang, 2001), 生防潜力极 大。由于索科线虫在自然界的分布和数量有限, 加 之近年化学农药在蔬菜和粮棉油等作物生产上的 广泛使用，在杀死昆虫的同时，也使农田害虫天敌 资源受到很大杀伤，甚至导致某些昆虫天敌有消失 灭种的危险，在害虫高发的季节更是难有足够线虫

\footnotetext{
收稿日期：2012-04-05; 接受日期：2012-08-31

基金项目: 国家自然科学基金(30870350)

“通信作者(Corresponding author), Tel: 027-67862730, Email: wangguoxiu@ yahoo.com.cn

第一作者简介: 吴运梅, 女, 硕士研究生, 研究方向为动物生化与分子生物学; E-mail: wlaug@163.com
} 
资源量与之匹配而起到生物防治的效果。为解决这 一问题，近年国内、外有关学者试图模拟昆虫体内 血淋巴环境体外培养索科线虫, 但均未获得成功 (Wang et al, 2001), 其主要原因是培养的线虫不能 完成性别分化及成熟。因此, 对昆虫病原索科线虫 性别分化机制的研究不仅具有重要的理论意义, 而 且具有重大的应用价值。

目前, 对索科线虫性别分化机制的研究, 主要 停留在形态学、组织学和生理生化等方面( Li et al, 2006), 对其分子机理的探讨尚处在起步阶段。 $\mathrm{He}$ et al (2009)和 Ren et al (2011a, b)分别克隆了性别 决定关键基因 $t r a-1$ 部分片段和性腺发育相关基 因 vasa 全长 cDNA 序列; Gao et al (2004)通过 mRNA 差异显示技术和双向电泳技术分别从转录 和蛋白水平对雌雄成虫的基因表达进行了分析, 发现䧳雄成虫基因表达在 RNA 和蛋白水平均存 在明显差异，但由于当时实验条件的限制，他们 并未进行更深入的研究。然而, 基于近年生理生 化和形态学研究进展, 发现寄生后期线虫是其性 腺发生和分化的重要时期 ( Li et al, 2006), 研究该 时期线虫的基因表达状况对于了解中华卵索线虫 的性别分化机制具有重要意义, 但对该时期的研 究迄今仍很贵乏。因此, 为了解线虫性腺发育的分 子机制, 分析雌雄线虫性腺发育关键时期基因表达 差异，在查阅国内外相关文献的基础上，本研究利 用 mRNA 差异表达技术, 分析了寄生后期早期阶段 雌、雄幼虫的基因表达差异, 并利用 24 对引物对该 时期的雌雄虫的全部 mRNA 进行篮查, 试图分离到 线虫性腺发育关键期雌雄虫的差异表达基因片段, 从而为探明中华卵索线虫性别分化机制奠定 基础。

\section{1 材料与方法}

\section{1 实验材料}

1.1.1 实验动物 中华卵索线虫采自河南省上蔡 县麦田, 利用宿主棉铃虫在本实验室长期传代培养 备用。

1.1.2 主要试剂 PMD 18-T、Rnase-Free DNase、 T4 DNA Ligation Kit、T4 DNA Ligase、 Primerscript reverse transcriptase 载体购自 TaKaRa 公司; E.Z.N.A.TM Gel Extraction Kit 购自 Omega bio-tek; Taq DNA polymerase 购自 Fermentas 公司; TRIZOL REAGENT 购自 Invitrogen 公司。其它试剂均为分
析纯，购自国内化学试剂公司。

1.1.3 引物序列 3' 针定引物: (1) H-T11A: 5'AAGCTTTTTTTTTTTA-3'; (2) H-T11C: 5'-AAGCT TTTTTTTTTTC-3'; (3) H-T11G: 5'-AAGCTTTTTT TTTTTG-3'。

5' 随机引物: (1) H-AP1: 5'-AAGCTTGATT GCC-3'; (2) H-AP2: 5'-AAGCTT CGACT GT-3'; (3) H-AP3: 5'-AAGCTTTGGTCAG-3'; (4) H-AP4: 5'AAGCTTCTCAACG-3'; (5) H-AP5: 5'-AAGCTTA GTAGGC-3'; (6) H-AP6: 5'-AAGCTTGCAC CAT-3'; (7) H-AP7: 5'-AAGCTTAACGAGG-3'; (8) H-AP8: 5'-AAG CTTTTACCG C-3'。

\section{2 实验方法}

1.2.1 中华卵索线虫雌、雄寄生后期幼线虫的获取 取中华卵索线虫感染期幼虫，按线虫与宿主 100:1 和 5:1 的比例分别感染棉铃虫, 收集不同时间自然 脱出的雌、雄寄生后期幼线虫, 无菌水洗净后置于 潮湿沙子中, 放入 $26{ }^{\circ} \mathrm{C}$ 培养箱培养。

培养 $5 \mathrm{~d}$ 后取出, 于超净工作台中用 DEPC 水 清洗净, 然后取适量装入 DEPC 处理过的 EP 管中, 液氮速冻后，置于 $-80{ }^{\circ} \mathrm{C}$ 冰箱备用。

1.2.2 中华卵索线虫 RNA 的制备 按 Trizol 试剂 使用说明并结合本实验材料的特点, 分别提取雌、 雄中华卵索线虫寄生后期幼虫的总 RNA。

1.2.3 RNA 中痕量基因组 DNA 的去除 利用 RNase-free DNase I 去除残留的中华卵索线虫基因 组 DNA, RNA 的完整性通过琼脂糖凝胶电泳检测, 利用分光光度计检测 RNA 的浓度和纯度。分别以 经过 DNase I 处理的 RNA、RNA 反转录成的 cDNA、 超纯水扩增 actin 基因, 其中 cDNA 作为阳性对照, 超纯水作为阴性对照, 检测 DNA 是否完全去除。

1.2.4 mRNA 差异显示 PCR cDNA 第一链的合 成: 在 $0.2 \mathrm{~mL}$ 离心管中依次加入: 针钉引物 (20 $\mu \mathrm{mol} / \mathrm{L}) 1 \mu \mathrm{L}, \mathrm{dNTP}(10 \mathrm{mmol} / \mathrm{L}) 1 \mu \mathrm{L}$ ，中华卵索线虫 总 RNA $2 \mu \mathrm{g}$, RNase-free 水补至 $14 \mu \mathrm{L}$; 然后 PCR 仪中 $65{ }^{\circ} \mathrm{C}$ 处理 $10 \mathrm{~min}$, 立即冰浴 $1 \mathrm{~min}$; 稍离心后, 加入 RNase Inhibitor(40 U/ $\mu \mathrm{L}) 1 \mu \mathrm{L}, 5 \times$ First-Strand Buffer $4 \mu \mathrm{L}$; 混匀, 稍离心, PCR 仪中 $42{ }^{\circ} \mathrm{C}$ 温育 2 $\mathrm{min}$; 加入 $1 \mu \mathrm{L}$ primscript reverse transcriptase (200 $\mathrm{U}$, 购自 TaKaRa 公司); 轻轻混匀后, PCR 仪中 $42{ }^{\circ} \mathrm{C}$ 温育 $50 \mathrm{~min}$; PCR 仪中 $70{ }^{\circ} \mathrm{C}$ 处理 $15 \mathrm{~min}$ 以 灭活反转录酶; 立即进行第二链的合成或 $-20{ }^{\circ} \mathrm{C}$ 保存。 
cDNA 第二链的合成: 在 $0.2 \mathrm{~mL}$ 离心管中加入 第一链针钉引物 $(20 \mu \mathrm{mol} / \mathrm{L}) 1 \mu \mathrm{L}$, 第二链随机引物 $(20 \mu \mathrm{mol} / \mathrm{L}) 1 \mu \mathrm{L}, \mathrm{cDNA}$ 第一链产物 $2 \mu \mathrm{L}, 10 \times \mathrm{PCR}$ 缓冲液 $2 \mu \mathrm{L}, 10 \mathrm{mmol} / \mathrm{L}$ dNTPs $0.4 \mu \mathrm{L}, 25 \mathrm{mmol} / \mathrm{L}$ $\mathrm{MgCl}_{2} 1.4 \mu \mathrm{L}$, 无菌水补至 $19 \mu \mathrm{L}$; PCR 仪中, $96{ }^{\circ} \mathrm{C}$ 处理 $10 \mathrm{~min}$ 后, $36{ }^{\circ} \mathrm{C}$ 处理 $15 \mathrm{~min}$; 然后加入 $1 \mu \mathrm{L}$ Taq 酶 $(1 \mathrm{U} / \mu \mathrm{L})$; 按以下程序进行 PCR 扩增: $94{ }^{\circ} \mathrm{C} 5$ $\min , 94{ }^{\circ} \mathrm{C} 45 \mathrm{~s}, 40{ }^{\circ} \mathrm{C} 2 \mathrm{~min}, 72{ }^{\circ} \mathrm{C} 1.5 \mathrm{~min}, 40$ 循环, $72{ }^{\circ} \mathrm{C} 10 \mathrm{~min}$; 然后 $-20{ }^{\circ} \mathrm{C}$ 保存备用。

1.2.5 变性聚丙烯酰胺凝胶电泳 分别取 $3.5 \mu \mathrm{L}$ 差 异显示 PCR 产物加入 $2 \mu \mathrm{L}$ 变性聚丙烯酰胺凝胶上 样缓冲液( $95 \%$ 去离子甲酰胺, $20 \mathrm{mmol} / \mathrm{L}$ EDTA, $0.05 \%$ 溴酚兰, $0.05 \%$ 二甲苯蓝), $95{ }^{\circ} \mathrm{C}$ 变性 $3 \mathrm{~min}$, 然后使用 TBE 缓冲液在 $6 \%$ 的变性聚丙烯酰胺凝胶 上进行电泳, $400 \mathrm{~V}$ 电泳大约 $6 \mathrm{~h}$ 即可完全分离, 然 后取下凝胶，采用银染的方法显色。该方法快速简 便, 分辨率高。

1.2.6 差异 cDNA片段的回收 用干净手术刀切下 雌、雄有表达差异的 DNA 片段, 放入 $0.5 \mathrm{~mL}$ 离心 管中; 加入 $20 \mu \mathrm{LTE}$ 浸泡胶条, 并于 $95{ }^{\circ} \mathrm{C}$ 处理 20 min, 使凝胶中的 DNA 片段溶入 TE 缓冲液。

1.2.7 差异 cDNA片段克隆与分析 以浸泡液为模 板，按上述条件对差异片段再扩增; PCR 产物经琼 脂糖凝胶回收目的片段后, 与 $\mathrm{pMD}-19 \mathrm{~T}$ 载体连接, 然后经大肠杆菌转化、篮选后, 送样测序, 所得序 列在 NCBI 和 Ensemble 上进行比较分析, 初步确定 其功能。

\section{2 结果与分析}

\section{1 雌、雄寄生后期幼线虫的收集}

中华卵索线虫寄生期的营养竞争压力决定其 雌、雄性别分化。当感染比率较低时(5:1), 营养竞争 压力较小、寄生期的时间较长 $(>10 \mathrm{~d})$, 每条线虫在 宿主血淋巴中获得的营养较多, 所以发育成的寄生 后期幼线虫虫体较大，且基本上都为雌虫; 而感染 率较高时(100:1), 营养竞争压力较大、寄生期的时 间较短 $(\sim 7 \mathrm{~d})$, 发育成的寄生后期幼线虫虫体较小, 且通常都为雄虫。因此, 根据感染比例、寄生时间 及虫体大小来区分并收集雌、雄寄生后期幼线虫。

\section{2 中华卵索线虫 RNA 的提取}

分别提取雌、雄寄生后期幼线虫总 RNA，用 Nanodrop 分光光度计分别测定其纯度与浓度。结果 $80 \mathrm{mg}$ 线虫材料大约可得 $60 \mu \mathrm{g}$ 的总 RNA,
OD260/280 和 OD260/230 值分别为 1.9 和 2.0 左右, 琼脂糖凝胶电泳图中(图 1)28S、18S 和小 RNA 三条 带均清晰可见。

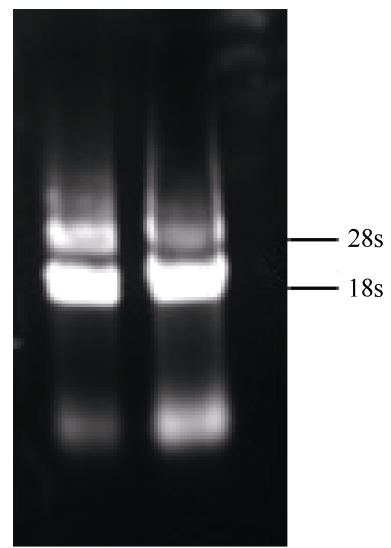

图 1 中华卵索线虫总 RNA

Fig. 1 Total RNA of Ovomermis sinensis

\subsection{RNA 的 DNA 酶处理}

选取浓度和纯度均符合要求的雌、雄虫总 RNA 样品, 用 DNase I 处理, 以除去其中痕量 DNA, 以 提高实验准确性。处理后琼脂糖凝胶电泳图中三条 带仍清晰可见，说明纯化后的 RNA 仍具有较高完 整性; 且以经 DNase I 处理的 RNA 和阴性对照为模 板没有扩增出 actin 基因, 而以 cDNA 为模板的阳性 对照可扩增出(图 2)。因此，可以证明经过 DNase I 处理后的 RNA 已完全去除了基因组 DNA。

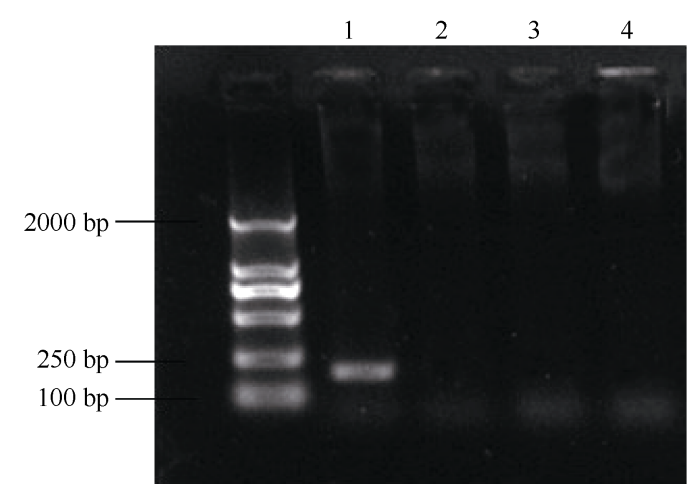

图 2 中华卵索线虫总 RNA 中残留基因组 DNA 的检测 Fig. 2 Detection of DNA in total RNA of Ovomermis sinensis 1) 线虫 cDNA 为模板扩增 $a c t i n ; 2)$ 水作对照扩增 actin; 3) 䧳线虫 RNA 为模板扩增 actin; 4) 雄线虫 RNA 为模板扩增 actin。

1) Amplification of actin using cDNA of $O$. sinensis; 2) Amplification of actin using ultrapure water; 3) Amplification of actin using RNA of female $O$. sinensis; 4) Amplification of actin using RNA of male $O$. sinensis.

\section{4 差异显示 PCR}

DD-PCR 产物在 $6 \%$ 的变性聚丙烯酰胺凝胶上 
电泳, 银染显示条带(图 3)。只有同一条件下三个重 复均出现某一条带, 而相比较的另一条件下均未出 现该条带, 才被认为是差异条带, 用无菌手术刀切 下。共收集到 33 条差异条带。

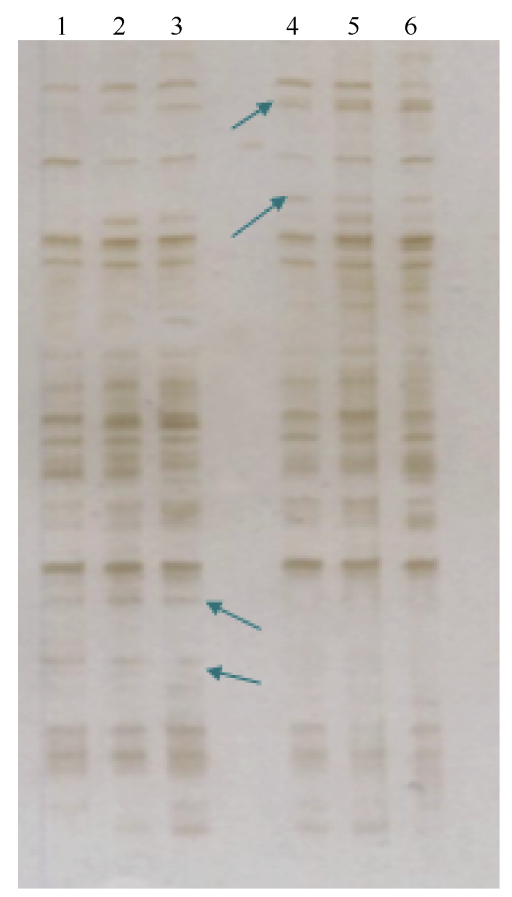

图 3 部分 DD-PCR 结果(箭头指示差异条带)

Fig. 3 Partial result of DD-PCR (arrows show differential fragments)

1-3: 雌虫重复 DD-PCR 产物(H-T11C 与 H-AP8 扩增); 4-6: 雄虫重复 DD-PCR 产物(H-T11C 与 H-AP8 扩增)。

1-3: Repeat DD-PCR of female Ovomermis sinensis (Amplification by H-T11C and H-AP8); 4-6: Repeat DD-PCR of male $O$. sinensis (Amplification by $\mathrm{H}-\mathrm{T} 11 \mathrm{C}$ and H-AP8).

\section{5 差异 cDNA 片段的重扩增、克隆与测序}

以切下的差异片段洗脱液为模板, 并分别用相 应的针钉引物和随机引物重新扩增差异条带。33 条 差异条带中有 13 条重扩增回收失败, 最终获得 20 条差异条带。其中 8 条在雄虫体内特异表达, 12 条 在雌虫体内特异表达, 此 20 条带经测序后获得其 核苗酸序列。

\section{6 差异 cDNA 片段的比对}

将所得核苷酸序列在 NCBI 上进行 blastx 分析 发现, 其中 4 条(雌 G5-4、雌 G8-1、雄 C7-3、雄 C7-4) 与已知序列无任何同源性, 余下 16 条大多编码假 定蛋白(推测蛋白)(表 1)。为进一步了解所分离片段 的功能信息, 利用 ensembl 网站, 分析所得序列与
秀丽线虫等 5 个物种基因组序列的同源性，其中 10 个片段与所比对 5 个物种基因组序列无任何匹配片 段, 其余 10 个片段比对结果见表 2。其中, 雌 G7、 雄 G8-5、雄 C2、雄 C7-3 等 4 个片段与秀丽线虫 X 染色体具有同源片段(同源性比例分别为 $49 \%$ 、 $44.87 \% 、 36.49 \% 、 33 \%$ ), 雌 C6-1、雌 G5-3、雌 G5-2、 雌 A5-1、雄 A5-2 和雄 C8-4 分别与果蝇 3L 染色体、 果蝇 U 染色体、秀丽线虫 IV 号染色体、秀丽线虫III 号染色体、秀丽线虫(包括海鞘及酿酒酵母)的 rRNA 基因和秀丽线虫 II 号染色体具有部分同源性。

\section{3 讨 论}

Li et al (2006)通过石蜡横切片观察了中华卵索 线虫生殖腺重要发育时期形态变化, 发现寄生后期 幼线虫在刚从宿主体内脱出时其生殖腺极小, 很难 观察到, 滋养物体占满虫体整个假体腔; 蜕皮后的 雌性成虫其生殖腺已发育完全。推测其生殖腺的发 育开始于寄生后期幼线虫到蜕皮为成虫这一过程 中, 寄生后期是线虫性腺发育的关键时期。为此, 本研究选择寄生后期幼线虫作为差异显示分析的 研究材料。

分析雌、雄线虫基因表达状况是探究中华卵索 线虫性别分化机制的重要工作，但由于该线虫的生 活周期较长, 难于准确确定线虫性别分化的具体时 期, 目前其遗传背景也较为欠缺, 通过普通的基因 克隆技术难于获得性别分化相关基因，因此，长期 以来这方面的研究进展缓慢。本研究避开这些困难, 采用 $\mathrm{mRNA}$ 差异显示技术分析了线虫性腺发育关 键时期雌、雄线虫基因的表达差异, 并在本实验室 首次通过该技术分离到差异表达基因片段, 为后续 研究奠定了良好基础。

通过 mRNA 差异显示技术共分离到 20 条雌、 雄寄生后期幼虫差异表达基因片段, 其中 8 条在雄 虫体内特异表达, 12 条在䧳虫体内特异表达, 通过 在 NCBI 上进行 blast 分析发现所分离差异片断中, 有 4 个序列与已知序列不存在任何同源性, 余下的 16 条片段大多编码的为假定蛋白(推测蛋白)。可能 原因为实验材料遗传背景不详, 国内外对该线虫及 其近源物种分子生物学研究较少, 数据库上所具有 的相似序列较少, 因此, 本文所分离的片段大多难 以确定其来源和功能。然而, 用 Ensembl 对所分离 到的 20 条差异序列进行分析时发现雌 G7、雄 G8-5、 
表 1 差异片段的同源性分析

Tab. 1 Homology analyses of DNA fragments derived from DD-PCR products

\begin{tabular}{|c|c|c|c|c|c|c|}
\hline $\begin{array}{c}\text { 编号 } \\
\text { No. }\left(+0^{\circledR}\right)\end{array}$ & $\begin{array}{l}\text { 长度 } \\
\text { Length } \\
\text { (bp) }\end{array}$ & $\begin{array}{c}\text { 序列同源性比对 } \\
\text { Sequence homology }\end{array}$ & $\begin{array}{c}\text { GenBank 序列登 } \\
\text { 录号 GenBank } \\
\text { Accession no. }\end{array}$ & $P$ & $\begin{array}{c}\text { 一致性 } \\
\text { Identity (\%) }\end{array}$ & $\begin{array}{c}\text { 相似性 } \\
\text { Similarity (\%) }\end{array}$ \\
\hline 雌 C7-1 & 341 & $\begin{array}{l}\text { PREDICTED: similar to vomeronasal } \\
\text { V1r-type receptor V1rj4 }\end{array}$ & XP_001520335.1 & 2.2 & $19 / 51(37 \%)$ & $25 / 51(49 \%)$ \\
\hline 雌 C6-1 & 358 & PREDICTED: titin-like & XP_002739922.1 & $1 e-06$ & $31 / 98(31 \%)$ & $53 / 98(54 \%)$ \\
\hline 雌 A5-1 & 773 & ADP, ATP carrier protein & XP_001895160.1 & $2 e-56$ & $104 / 127(81 \%)$ & $116 / 127(91 \%)$ \\
\hline 雌 A5-3 & 348 & predicted protein & XP_002680011.1 & 6.5 & $17 / 60(28 \%)$ & $31 / 60(51 \%)$ \\
\hline 雌 G7 & 406 & GF11865 & XP_001959783.1 & $3 e-30$ & $61 / 118(51 \%)$ & $91 / 118(77 \%)$ \\
\hline 䧳 A4-1 & 445 & hypothetical protein TRIADDRAFT_50766 & XP_002115731.1 & $2 \mathrm{e}-08$ & $27 / 46(58 \%)$ & $36 / 46(78 \%)$ \\
\hline 䧳 G5-3 & 529 & hypothetical protein LELG_02536 & XP_001525979.1 & $1 e-06$ & $34 / 146(23 \%)$ & $62 / 146(42 \%)$ \\
\hline 雌 G5-2 & 723 & predicted protein & EEH52651.1 & 0.037 & $43 / 119(36 \%)$ & $51 / 119(42 \%)$ \\
\hline 雌 C8-2 & 484 & Pc12g04650 & XP_002557334.1 & 0.003 & $27 / 49(55 \%)$ & $34 / 49(69 \%)$ \\
\hline 䧳 C8-1 & 573 & conserved hypothetical protein & EEE27292.1 & 0.31 & $24 / 77(31 \%)$ & $43 / 77(55 \%)$ \\
\hline 雄 G8-5 & 367 & Probable exocyst complex component Sec15 & XP_001893932.1 & $4 \mathrm{e}-20$ & $60 / 90(66 \%)$ & $73 / 90(81 \%)$ \\
\hline 雄 A5-2 & 423 & hypothetical protein Bm1_04940 & XP_001892466.1 & $4 \mathrm{e}-17$ & $46 / 64(71 \%)$ & $50 / 64(78 \%)$ \\
\hline 雄 C8-4 & 533 & hypothetical protein & XP_001685961.1 & $4 \mathrm{e}-05$ & $28 / 72(38 \%)$ & $38 / 72(52 \%)$ \\
\hline 雄 A3-1 & 165 & hypothetical protein $\mathrm{CaO} 19.1660$ & XP_721737.1 & 6.4 & $20 / 50(40 \%)$ & $28 / 50(56 \%)$ \\
\hline 雄 $\mathrm{C} 2$ & 505 & conserved hypothetical protein & XP_002433206.1 & $5 e-09$ & $36 / 108(33 \%)$ & $55 / 108(50 \%)$ \\
\hline 雄 C3-3 & 470 & hypothetical protein Bm1_44150 & XP_001900292.1 & $6 e-14$ & $44 / 105(41 \%)$ & $58 / 105(55 \%)$ \\
\hline
\end{tabular}

表 2 差异片段的 Ensembl 分析

Tab. 2 Analyses of DNA fragments derived from DD-PCR products by Ensembl website

\begin{tabular}{|c|c|c|c|c|c|c|c|}
\hline \multirow{3}{*}{ 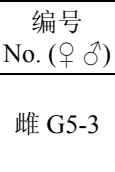 } & $\begin{array}{c}\text { 同源性 } \\
\text { Homology }\end{array}$ & ID & \multicolumn{5}{|c|}{$\begin{array}{c}\text { 物种/染色体定位 } \\
\text { Species/Chromosome localization }\end{array}$} \\
\hline & \multirow{2}{*}{$\begin{array}{l}\text { Lodderomyces elongisporus NRRL YB-4239 hypothetical } \\
\text { protein }\end{array}$} & \multirow{2}{*}{ XM_001525929.1 } & C. elegans & C. intestinalis & C. savignyi & Drosophila & \multirow{2}{*}{$\begin{array}{c}\text { Saccharo- } \\
\text { myces } \\
\text { no }\end{array}$} \\
\hline & & & no & no & no & $\mathrm{U}$ & \\
\hline 雌 G7 & Drosophila melanogaster kinesin-73 mRNA & U81788.1 & $\mathrm{X}$ & no & no & $2 \mathrm{R}$ & no \\
\hline 雌 A5-1 & $\begin{array}{l}\text { Caenorhabditis elegans Adenine Nucleotide Translocator } \\
\text { family member }\end{array}$ & NM_069326.2 & III & $4 \mathrm{Q}$ & no & $\mathrm{X}$ & II \\
\hline 雌 C6-1 & PREDICTED: Saccoglossus kowalevskii titin-like & XM_002739876.1 & no & no & no & $3 \mathrm{~L}$ & no \\
\hline 雌 G5-2 & & & IV & no & no & no & IV \\
\hline 雄 A5-2 & Brugia malayi hypothetical protein & XM_001892431.1 & I & 未定 & no & no & XII \\
\hline 雄 $\mathrm{C} 2$ & Pediculus humanus corporis conserved hypothetical protein & XM_002433161.1 & $\mathrm{X}$ & no & no & no & no \\
\hline 雄 C7-3 & & & $\mathrm{X}$ & no & no & no & no \\
\hline 雄 C8-4 & Leishmania major hypothetical protein & XM_001685909.1 & II & no & no & no & no \\
\hline 雄 G8-5 & Brugia malayi Probable exocyst complex component Sec15 & XM_001893897.1 & $\mathrm{X}$ & no & no & no & no \\
\hline
\end{tabular}

字母和罗马数字表示能与本文所分离片段相匹配的基因定位的染色体编号。

Letters and roman numerals in the table show chromosome numbers where genes are located, which have corresponding fragments in this study.

雄 C2、雄 C7-3 等 4 个片段与秀丽线虫 X 染色体具 有同源片段。雌 G7 片段与果蝇中定位于 $2 \mathrm{R}$ 染色体 上的基因 $k h c-73$ 和秀丽线虫中定位于 $\mathrm{X}$ 染色体上 的基因 $k l p-4$ 同源性都较高(分别为 50\%和 49\%), 其 中 $k h c-73$ 编码蛋白 kinesin-73、klp-4 编码蛋白 KLP-4, 且秀丽线虫中 KLP-4 和果蝇中 kinesin-73 为直系同 源蛋白, 说明本实验所分离的中华卵索线虫的雌
G7 片段可能与秀丽线虫中的 $k l p-4$ 基因和果蝇中的 $k h c-73$ 基因为同源基因。而 $k l p-4$ 位于秀丽线虫 $\mathrm{X}$ 染色体上，通过 RNA 干扰技术发现 KLP-4 功能缺 失个体并无任何发育异常, 因此, KLP-4 蛋白在秀 丽线虫发育和行为中扮演的具体角色还未确定 (Ensembl 网页)。但是，基于序列相似性分析，推测 KLP-4 可能在神经元的发育和功能方面具有一定作 
用。至于该基因是否与线虫性别分化和性腺发育有 关还需进一步证实。

秀丽线虫中 $X$ 染色体对线虫的性别分化方向 具有重要作用, $\mathrm{X}$ 染色体上的基因 fox-1 和 sex-1 为 性别分化方向控制的初始信号 (Akerib \& Meyer, 1994), 它们通过控制性别决定基因 xol-1 的活性来 实现对 X 染色体上一系列性别分化级联通路基因 的控制(Hodgkin, 2002; Large \& Mathies, 2007)。由 此可见，秀丽线虫 X 染色体在性别分化中具有关键 作用，而通过 ensembl 分析，本文所分离的上述 4

\section{参考文献:}

Akerib CC, Meyer BJ. 1994. Identification of X chromosome regions in Caenorhabditis elegan that contain sex-determination signal elements [J]. Genetics, 138(4): 1105-1125.

Chen G, Jian H, Ren HF, Pan CS. 1991. A new species of parasitic nematode of armyworm: Ovomermis sinensis sp. nov. (Nematoda: Mermithidae) [J]. Acta Zootax Sin, 16(3): 270-277. [陈果, 简恒, 任惠芳, 潘沧桑. 1991. 寄生于粘虫的卵索线虫属一新种-中华卵索线虫(线虫纲: 索 科). 动物分类学报, 16(3): 270-274.]

Gao Y, Wang GX, Chen SL. 2004. Preliminary analysis on dissoluble protein of Ovomermis sinensis adults by Z-D PAGE [J]. Acta Zool Sin, 50(1): 141-144. [高原, 王国秀, 陈思礼. 2004. 中华卵索线虫雌雄成 虫可溶性蛋白双向电泳分析. 动物学报, 50(1): 141-144.]

He JF, Wang WN, Zhou QC, Wang GX. 2009. cDNA cloning and quantitative analysis by real-time RT-PCR of tra- 1 gene in Ovomermis sinensis [J]. Acta Phytophyl Sin, 36(4): 324-328. [贺俊飞, 王伟娜, 周 青春, 王国秀. 2009. 中华卵索线虫 $t r a-1$ 基因 cDNA 片段的克隆及 实时定量表达分析. 植物保护学报, 36(4): 324-328.]

Hodgkin J. 2002. Exploring the envelope: Systematic alteration in the sex-determination system of the nematode Caenorhabditis elegans [J]. Genetics, 162(2): 767-780.

Large EE, Mathies LD. 2007. Chromatin regulation and sex determination in Caenorhabditis elegans [J]. Trends Genet, 23(7): 314-317.

Li JL, Wang GX, Wang W, Liu XS, Qiao ZX, Zhao S. 2006. Changes of the
条差异表达片段均与秀丽线虫 $\mathrm{X}$ 染色体上的片段 具有较大同源性，提示上述四条片段可能与中华卵 索线虫性别分化有关，但这些片段是否为性别分化 关键基因，尚待进一步研究。

其余所分离的 10 条片段通过 Ensembl 分析未 发现与所分析 5 个物种具有同源性。推测可能为中 华卵索线虫特有或新基因序列, 在后续研究中可结 合 cDNA 文库分离出基因全长进行功能研究，或作 为索科线虫特有的分子标记将为其后续研究奠定 基础。

morphological and chemical substances of the Ovomermis sinensis during gonadial development [J]. J Central Chn Normal Univ: Nat Sci, 40(2): 265-269. [李俊莉, 王国秀, 汪威, 刘绪生, 乔志仙, 赵珊. 2006. 中华卵索线虫生殖系统发育程中形态和主要化学物质含量 的变化. 华中师范大学学报: 自然科学版, 40(2): 265-269.]

Ren S, Chen C, Liu X, Wang GX. 2011a. Molecular cloning and expression analysis of vasa gene in Ovomermis sinensis [J]. Acta Phytophyl Sin, 38(4): 333-338. [任爽，陈冲，刘绪生，王国秀. 2011b. 中华卵索线 虫 vasa 基因的克隆及其表达模式分析. 植物保护学报, 38(4): 333-338.]

Ren S, Wang WN, Zhao NN, Ai H, Wang GX. 2011b. Research progresses and prospects of nematode, Ovomermis sinensis [J]. Chn J Appl Entomol，48(3): 716-719. [任爽，王伟娜，赵娜娜，艾欢，王国秀. 2011a. 中华卵索线虫的性别分化分子机理研究进展. 应用昆虫学 报, 48(3): 716-719.]

Wang GX, Chen QH, Chen G. 2001. In Vitro cultivation of the Entomogenous nematode Ovomermis sinensis [J]. Acta Zool Sin, 47(2): 235-239. [王国秀, 陈曲侯, 陈果. 2001. 中华卵索线虫 的体外培养. 动物学报, 47(2): 235-239.]

Zhong YL, Wang GX. 2001. Advances in the studies on mermithidae in China [J]. Chn J Biol Control, 17(1): 35-39. [钟玉林, 王国秀. 2001. 我国昆虫寄生索科线虫研究近况. 中国生物防治, 17(1): 35-39.] 